Fuel Chemistry Division Preprints, American Chemical Society

\title{
AN IN SITU EXAMINATION OF THE FE SPECIES IN THE ARGONNE PREMIUM COAL SAMPLES USING X-RAY ABSORPTION SPECTROSCOPY
}

\author{
Stephen R. Wasserman, Randall E. Winans, Kathleen A. Carrado \\ Chemistry Division \\ Argonne National Laboratories \\ 9700 South Cass Avenue \\ Argonne, Illinois 60439
}

\section{DISCLAIMER}

This report was prepared as an account of work sponsored by an agency of the United States Government. Neither the United States Government nor any agency thereof, nor any of their employees, makes any warranty, express or implied, or assumes any legal liability or responsibility for the accuracy, completeness, or usefulness of any information, apparatus, product, or process disclosed, or represents that its use would not infringe privately owned rights. Reference herein to any specific commercial product, process, or service by trade name, trademark, manufacturer, or otherwise does not necessarily constitute or imply its endorsement, recommendation, or favoring by the United States Government or any agency thereof. The views and opinions of authors expressed herein do not necessarily state or reflect those of the United States Government or any agency thereof.

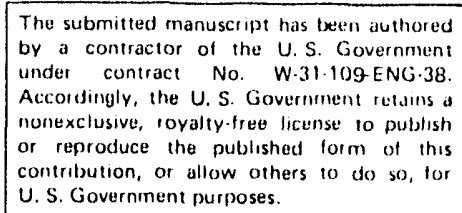




\title{
AN IN SITU EXAMINATION OF THE FE SPECIES IN THE ARGONNE PREMIUM COAL SAMPLES USING X-RAY ABSORPTION SPECTROSCOPY
}

\author{
Stephen R. Wasserman, Randall E. Winans, and Kathleen A. Carrado \\ Chemistry Division \\ Argonne National Laboratory \\ 9700 S. Cass Ave. \\ Argonne, IL 60439
}

Keywords: XAS, XANES, EXAFS, iron, coals, neural networks

\section{Introduction}

The elucidation of the inorganic materials within coals is particularly important for coal processing, since these compounds may function as in situ catalysts for coal liquefaction. In addition, these species will have to be separated from the organic species prior to the use of coal as a fuel or chemical feedstock, a process that will be facilitated by detailed knowledge of the materials to be removed. In recent years, X-ray absorption spectroscopy (XAS) has been used to probe the trace transition metals which are contained within the matrix of coals, ${ }^{1,2}$ as well as the nitrogen ${ }^{3}$ and sulfur ${ }^{4}$ functionality within organic coal constituents. Here we present the results of XAS studies, both near edge (XANES) and extended fine structure (EXAFS), on the iron species present within the eight Argonne Premium Coal Samples (APCS). Our aim is to provide at least a semi-qualitative analysis of the composition of the iron moieties in these particular coals. Previously the determination of Fe species in coals has been the province of Mössbauer spectroscopy 5,6 although the surface iron species of the Argonne coals have also been examined by XPS. ${ }^{7}$ Because of the availability of these alternative methods for analyzing iron, XAS has not been applied, in general, for this element. Here we compare the results from XAS with those previously found by Mössbauer spectroscopy for the Argonne premium coals. ${ }^{6}$

\section{Experimental}

X-ray absorption spectra were taken on fresh Argonne Premium Coals, which were removed from their containers and mounted in holders two days prior to acquisition of the spectra. The absorption spectra were acquired at beamlines X23-A2 and X19A of the National Synchrotron Light Source. The beamlines were equipped with Si[311] (X23) and Si[220] (X19) double crystal monochromators. Harmonics were rejected on X 19 by detuning of the monochromator. Transmission spectra were collected using ion chambers with nitrogen fill gas. A Lytle detector with argon fill gas was utilized for the fluorescence data. The energy calibration was maintained by monitoring the maximum at $7112 \mathrm{eV}$ in the derivative spectrum of $\mathrm{Fe}$ foil. The reported data are the average of 2 scans.

\section{Results}

For convenience we have divided the eight Argonne Premium Coals into two groups of four. The first set consists of those coals that contain sigiificant amounts of pyrite, $\mathrm{FeS}_{2}$. The Upper Freeport, Illinois, Pittsburgh, and Blind Canyon coals fall into this category. The absorption edges and radial structure functions for these samples are shown in Figure 1. The radial functions indicate the presence of long-range order about the iron, at least out to $8 \AA$.

The second set consists of the Wyodak-Anderson, Pocahontas, Lewiston-Stockton, and Beulah-Zap coals. Figure 2 presents the absorption edges and radial functions for these materials. In some of these samples, in particular the Beulah-Zap, the presence of pyrite is detected. But within this subset, both the absorption edges and the radial distributions

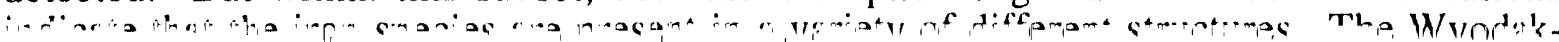


Anderson and the Beulah-Zap apparently contain similar mixtures of iron species, since the absorption edges are nearly identical. The EXAFS spectra suggest that, at least qualitatively, the other iron compounds in these four coals are not as well ordered as pyrite.

The analysis of mixtures of materials by XAS is somewhat problematical. We have used a new approach based on neural networks to separate the individual iron components. ${ }^{8}$ The advantage of this method is that spectra of standard compounds which exactly match the components of the system are not required. There is, however, an accompanying loss in numerical precision. The network was trained with authentic spectra of $\mathrm{FeO}, \mathrm{Fe}_{2} \mathrm{O}_{3}$, and $\mathrm{FeS}_{2}$, as well as simulated mixtures of these materials. These standards effectively provide a method for distinguishing between ferrous, ferric, and pyritic species in the coals. The resulting network was then verified using ferrous ammonium sulfate, magnetite ( $\left.\mathrm{Fe}_{3} \mathrm{O}_{4}\right)$, and a pyrite whose spectrum differed markedly in intensity from that which was used in the training process. Finally the network was used to analyze the near edge (XANES) spectra for each of the Argonne coals. The results of this analysis are shown in Table 1 . The numbers in parenthesis, when present, indicate the actual results from the neural network. Comparisons on duplicate samples indicate that these numbers are accurate to $\pm 10 \%$ absolute. 

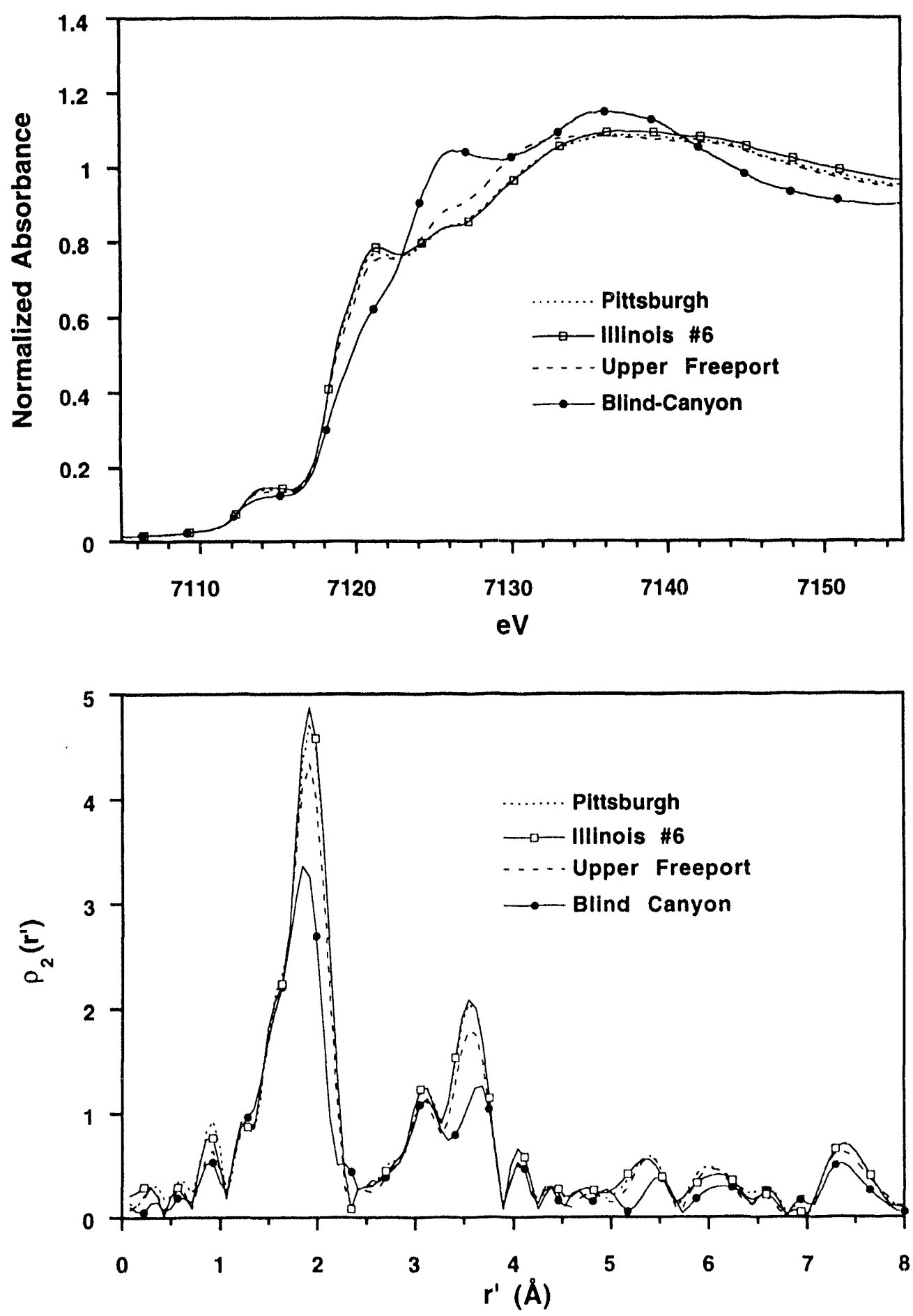

Figure 1. (top) X-ray absorption near edge spectra (XANES) and (bottom) radial structure functions for iron in Upper Freeport, Illinois \#6, Pittsburgh \#8, and Blind Canyon Coals 


\begin{tabular}{|c|c|c|c|}
\hline \multicolumn{4}{|c|}{ Iron Composition of Argonne Premium Coass } \\
\hline Coal & Ferrous (\%) & Ferric (\%) & Pyritic (\%) \\
\hline Upper Freeport & 10 & 2 & 88 \\
\hline Wyodak-Anderson & 7 & 59 & 32 \\
\hline Illinois \#6 & $0 \quad(-2)$ & 0 & $100(104)$ \\
\hline Pittsburgh \#8 & 0 & 0 & $100(101)$ \\
\hline Pocahontas \#3 & $90(111)$ & $10(12)$ & $0 \quad(-20)$ \\
\hline Blind Canyon & 28 & 8 & 62 \\
\hline Lewiston-Stockton & 51 & 43 & 5 \\
\hline Beulah-Zap & $0 \quad(-3)$ & 52 & 48 \\
\hline
\end{tabular}



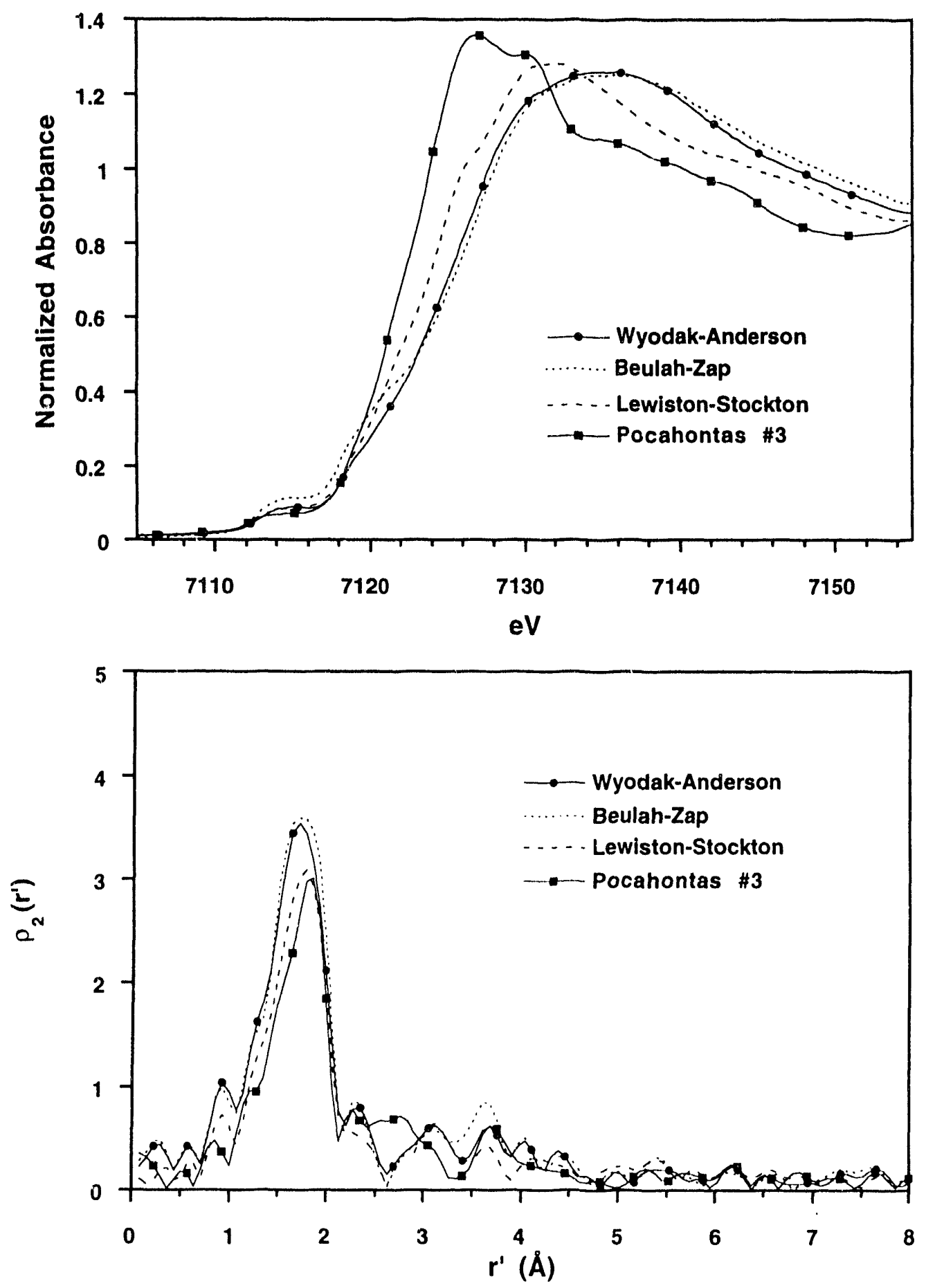

Figure 2. (top) X-ray absorption near edge spectra (XANES) and (bottom) radial structure functions for iron in Wyodak-Anderson, Beulah-Zap, Lewiston-Stockton, and Pocahontas \#3 Coals 
For seven of the eight coal samples, the results appear reasonable. However, in the case of Pocahontas, our analysis yields a significant negative percentage of pyrite, while the ferrous composition is over $100 \%$. We deduce that the Pocahontas coal consists primarily of ferrous species, but that the compounds present are not well represented by $\mathrm{FeO}$. The XANES and EXAFS spectra for this coal support this supposition. The edge spectrum of Pocahontas does not coincide with those of the other coals. In addition, there is an extra peak in the radial structure function at $2.6 \AA$ which is not found in the other premium samples. Both these observations indicate that the iron species in Pocahontas is unique among the APCS.

The iron compositions presented here are in approximate agreement with those from Mössbauer spectroscopy ${ }^{\mathfrak{G}}$ for the Upper Freeport, Illinois \#6, Pittsburgh \#8 and Blind Canyon coals. Significant discrepancies exist between the Mössbauer and XAS analyses for the remaining four samples. The question remains as to which technique results in the more reliable analysis. Fortunately, the radial structure functions provide an independent check on the pyrite content deduced from the analysis of the XANES spectra. The peak in the radial distribution at $3.6 \AA$ primarily results from an Fe-Fe interaction in pyrite. ${ }^{9}$ Figure 3 plots this feature for six of the APCS. (Pocahontas is omitted for the reasons discussed above, while the iron content of Illinois \#6 is virtually identical to that in Pittsburgh \#8). The intensity of this feature clearly correlates with the pyrite content as deduced from the near edge spectra. 


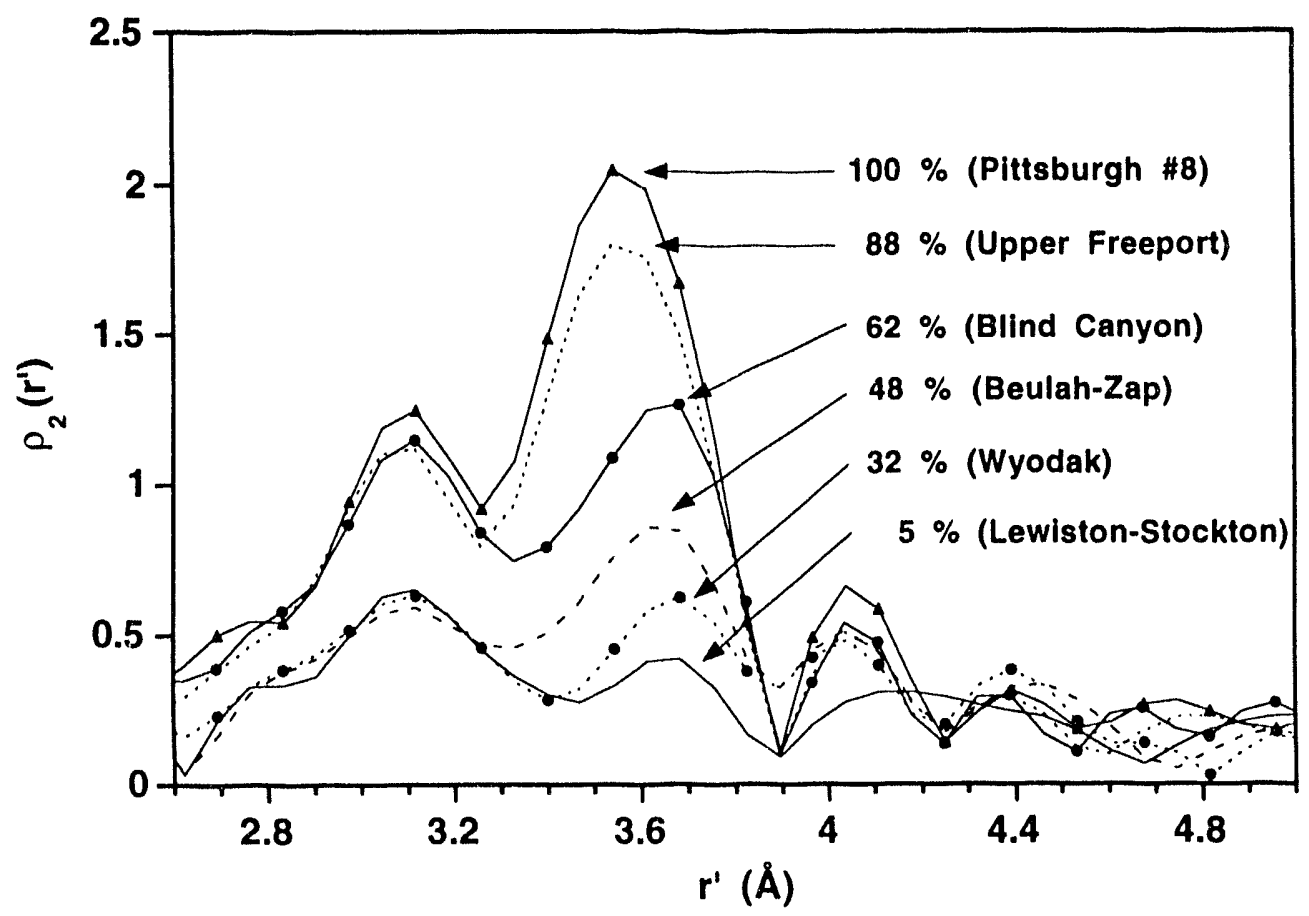

Figure 3. Intensity of Fe-Fe scattering in pyrite from EXAFS. The percentages of pyrite are those determined from XANES

\section{Summary}

We believe that XAS can reliably assign the various iron species present in coal in terms of $\mathrm{Fe}(\mathrm{II}), \mathrm{Fe}(\mathrm{III})$, and pyritic constituents. A search for the best representation of the iron species in Pocahontas is underway, since it does not appear to be well represented by the standards used in this investigation.

In addition, the application of neural networks to the analysis of XANES spectra has been demonstrated for the first time. This approach appears to be a viable method for the analysis of complex mixtures.

\section{Acknowledgment}

We would like to thank F. W. Lytle for providing several of the spectral standards for the neural network and K. Pandya for aid in obtaining some of the preliminary spectra for this study. This work was performed under the auspices of the Office of Basic Energy Sciences, Division of Chemical Sciences, U. S. Department of Energy, under contract number W-31-109-ENG-38. 


\section{References}

1. Huggins, F. E.; Shah, N.; Zhao, J.; Lu, F.; Huffman, G. P. Energy Fuels 1993, 7, 482-489.

2. Huggins, F. E.; Helble, J. J. ; Shah, N.; Zhao, J.; Srinivasachar, S.; Morency, J. R.; Lu, F.; Huffman, G. P. Prepr. Div. Fuel Chem. Am. Chem. Soc. 1993, 38, 265-271.

3. Mitra-Kirtley, S.; Mullins, O. C.; Branthaver, J.; van Elp, J.; Cramer, S. P. Prepr. Div. Fuel Chem. Am. Chem. Soc. 1993, 38, 762-768.

4. George, G. N.; Gorbaty, M. L.; Kelemen, S. R.; Sansone, M. Energy Fuels, 1991, 5, 9397.

5. Montano, P. A. Coal Structure, Advances in Chemistry Series, Vol. 192; Gorbaty, M. L. and Ouchi, K., Eds., American Chemical Society: Washington, D. C., 1981, pp. 337361.

6. Shah, N.; Keogh, R. A.; Huggins, F. E.; Huffman, G. P., Shah, A.; Ganguly, B.; Mitra, S. Prepr. Div. Fuel Chem. Am. Chem. Soc. 1990, 35, 784-792.

7. Kelemen, S. R.; Gorbaty, M. L.; George, G. N.; Kwiatek, P. J. Energy Fuels, 1991, 5, 720723.

8. Freeman, J. A. Simulating Neural Networks with Mathematica, Addison-Wesley Publishing Company: Reading, Massachusetts, 1994.

9. Brostigen, G.; Kjekshus, A. Acta Chem. Scan. 1969, 23, 2186-2188. 

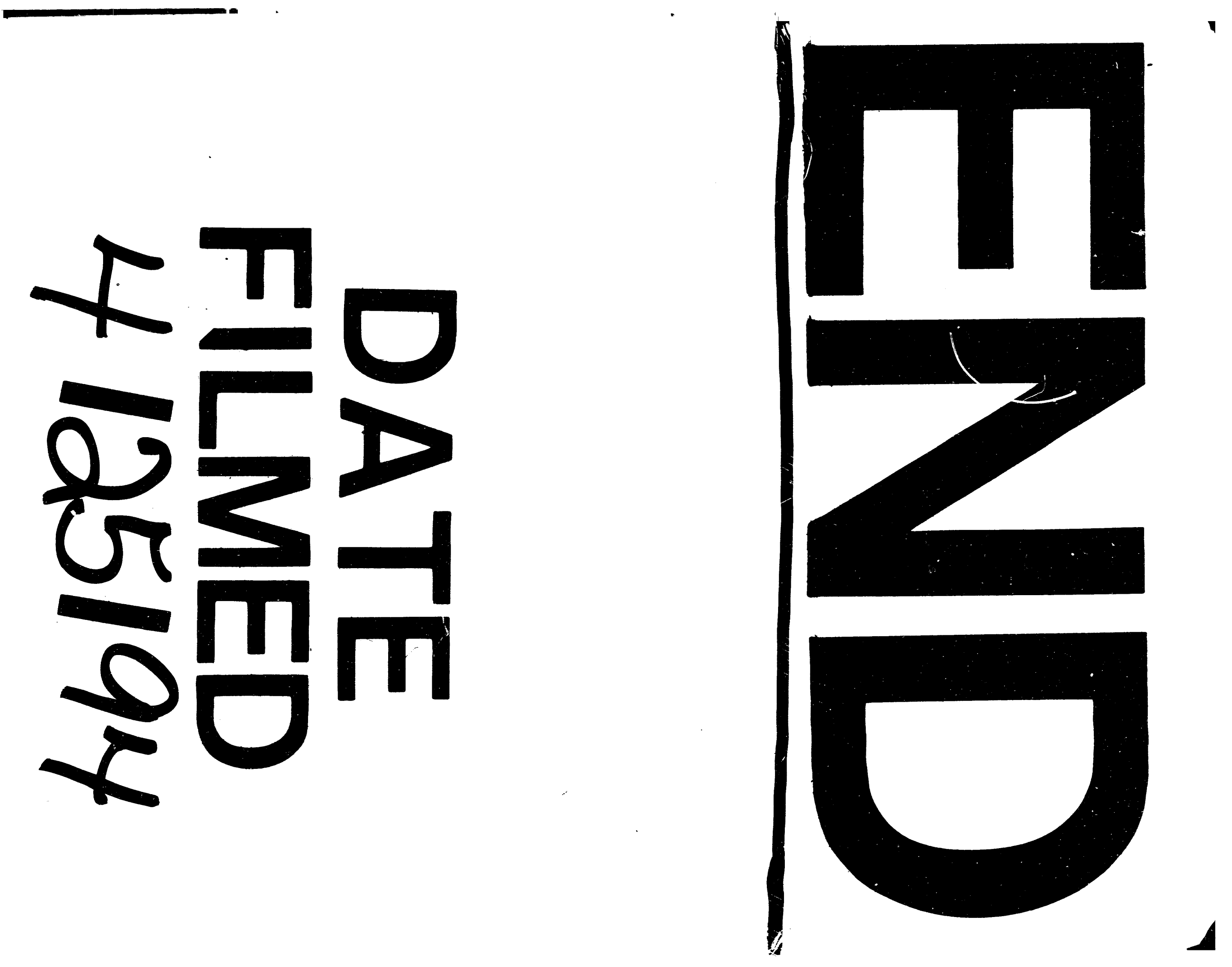


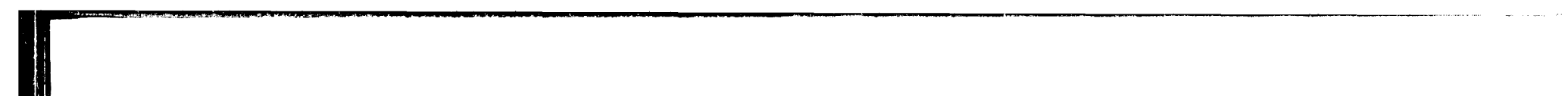

